\section{Editorial}

Check for updates

\section{OPEN ACCESS}

Received: Apr 3, 2019

Accepted: Apr 3, 2019

Address for Correspondence:

Beom Sun Chung, MD

Department of Anatomy, Ajou University School of Medicine, 164 World Cup-ro,

Yeongtong-gu, Suwon 16499,

Republic of Korea

E-mail: bschung@ajou.ac.kr

(C) 2019 The Korean Academy of Medical

Sciences.

This is an Open Access article distributed under the terms of the Creative Commons Attribution Non-Commercial License (https:// creativecommons.org/licenses/by-nc/4.0/) which permits unrestricted non-commercial use, distribution, and reproduction in any medium, provided the original work is properly cited.

ORCID iDs

Beom Sun Chung (iD)

https://orcid.org/0000-0002-3644-9120

\section{Disclosure}

The author has no potential conflicts of interest to disclose.

\title{
Let Clinicians Classify Emergency Patients
}

\author{
Beom Sun Chung (iD \\ Department of Anatomy, Ajou University School of Medicine, Suwon, Korea
}

- See the article "Changes in Relative Importance of the 5-Level Triage System, Korean Triage and Acuity Scale, for the Disposition of Emergency Patients Induced by Forced Reduction in Its Level Number: a Multi-Center Registry-based Retrospective Cohort Study" in volume 34, number 13, e114.

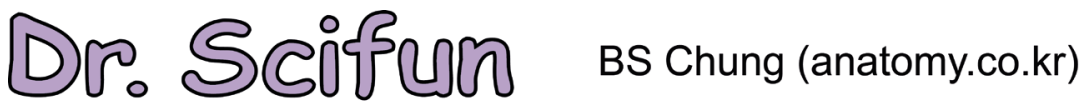

Let clinicians classify emergency patients.

In Korean emergency room, patients are classified into 5 levels.

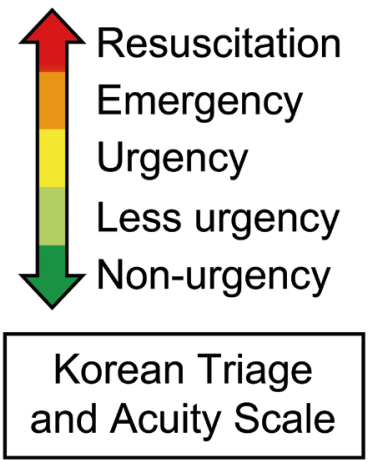

Korean government forces to classify patients into 2 levels for administrative convenience.

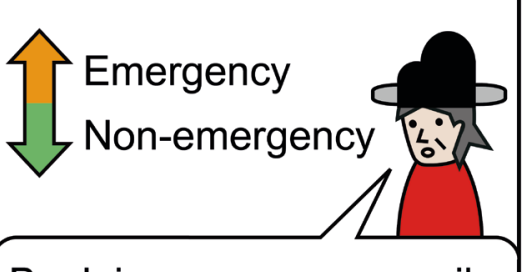

By doing so, we can easily charge non-emergency patients for expense.
According to 5 levels, treatment priority is decided objectively.

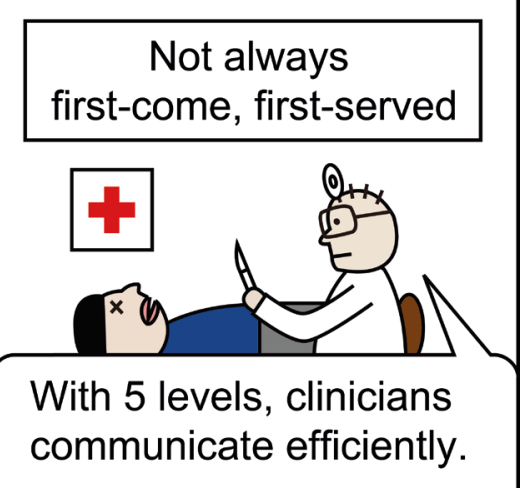

It is like putting 5 different foods into 2 plates, which is awkward.
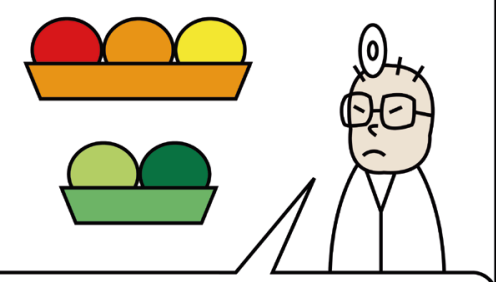

Why don't you integrate 5 government departments into 2 departments? 